\title{
The future of lignocellulose in Malaysian bioeconomy
}

\begin{abstract}
Lignocellulose is one of the most available and renewable resources from agricultural waste, forest residues, and municipal solid waste. Following the concept of waste-to-wealth, these biomasses are converted into high-value products. In addition, it will reduce waste generated and increase economic-efficiency towards bioeconomy. Thus, this chapter reviews the potential of lignocellulose and the achievements in the development of lignocellulose as one of the bioeconomy engines of growth in Malaysia. In order to develop further applications in the industry, it is best to understand the policy that supports and shapes the industrial development and the economic growth expected from lignocellulose. This chapter is based on the annual reports of the bioeconomy transformation program and several public documents published by other agencies. The documents were carefully gathered and analyzed based on the focus of this chapter.
\end{abstract}

Keyword: Pesticides; Indoxacarb; Toxicity; Zebrafish 